\title{
A RARE CASE OF SCHIZENCEPHALY
}

\author{
S. Sivaraman', K. Revathi², V. D. Raghavendran ${ }^{3}$
}

${ }_{1}^{1}$ Post Graduate, Department of Paediatrics, Sri Manakula Vinayagar Medical College and Hospital, Pondicherry.

${ }^{2}$ Post Graduate, Department of Paediatrics, Sri Manakula Vinayagar Medical College and Hospital, Pondicherry.

3 Professor and HOD, Department of Paediatrics, Sri Manakula Vinayagar Medical College and Hospital, Pondicherry.

ABSTRACT: Schizencephaly is rare form of neuronal migration disorder, which present early in life. We are presenting a case of 7 month old child, presents with multiple episodes of seizures, and neuroimaging revealed open lip schizencephaly.

KEYWORDS: Neuronal Migration Disorder, Schizencephaly.

HOW TO CITE THIS ARTICLE: S. Sivaraman, K. Revathi, V. D. Raghavendran. "A Rare Case of Schizencephaly." Journal of Evolution of Medical and Dental Sciences 2015; Vol. 4, Issue 93, November 19; Page: 15911-15912, DOI: 10.14260/jemds/2015/2315.

INTRODUCTION: Development of central nervous system is a highly complicated process and is organized in the following steps: Primary neurulation starts at 3-4 weeks of gestation, followed by prosencephalic development occurs at 2-3 months of gestation, neuronal proliferation starts at 3-4 months of gestation, and neuronal migration at the age of 3-5 months, followed by organization starts from 5 months of gestation to birth, and myelination after the birth will occur. We are presenting a case of neuronal migration disorder.

CASE: A 7 month old male child admitted with convulsion 8-10 episodes/day for the past 10 days. Seizure was generalized tonic clonic. Each episode lasting for 10-15min. Born for 3rd degree consanguinity, antenatal history unevenful. Normal vaginal delivery with history of birth asphyxia. Neonatal period child was not active, not taking feed properly. At $4^{\text {th }}$ month cataract was identified on both eyes and surgery done. Anthropometry microcephaly HC-34 $\mathrm{cm} \quad(<3 \mathrm{rd}$ centile), height $58 \mathrm{~cm} \quad(<3 \mathrm{rd}$ centile) and weight - $5.0 \mathrm{~kg}(<3 \mathrm{rd}$ centile). Delayed development - neck control not attained, not reaching for objects. Social smile attained at 7th month. On assessment Developmental Age was estimated as 3 months. Torch infection screening was negative.

MRI: Findings are bilateral open lip schizencephaly with hydrocephalus with communicating type with microcephaly. Microcalcifications were noted.

DISCUSSION: Schizencephaly is rare disorder, consists of unilateral or bilateral full thickness cleft of the cerebral hemispheres with communication between the ventricles and extra-axial subarachnoid spaces. The cleft commonly found in perisylvian areas.(1) The exact prevalence is unknown.

Financial or Other, Competing Interest: None.

Submission 09-10-2015, Peer Review 10-10-2015,

Acceptance 21-10-2015, Published 19-11-2015.

Corresponding Author:

Dr. S. Sivaraman

Post Graduate,

Department of Paediatrics,

Sri Manakula Vinayagar Medical College and Hospital,

Kalitheerthal Kuppam,

Pondicherry-605107.

E-mail: ssiva.dr@gmail.com

DOI:10.14260/jemds/2015/2315.
A study published in 2011 found a prevalence of 1.48 cases per 100,000 births in the UK.(2) The disorder was originally described by Yakovlev and Wadswoth. $(3,4)$

The schizencephaly classified into two variants by presentation (Type I)- "Fused" left in cerebral mantle as opposed to separated cleft or mantle with concordant "Hydrocephalus" (Type II).

They contend that the failure of normal migration of the primiti-ve normoblasts results in the cerebral cleft. $(3,4)$

The Schizencephaly etiology is not established because it is associated with several causes that includes genetic, toxic, metabolic and infectious factors. It is supposed that a focal ischemic necrosis or focal damage can destroy radial glial fibres during the early development of the cerebral cortex which helps in migration.(5) Hypothesis suggest that CMV infection during third or fourth month of gestation can involve disruption of radial glial cells guide.(6) Imaging may show subependymal or parenchymal calcification in many cases, which suggests that one cause of schizencephaly may be intrauterine infection with cytomegalovirus. (7)

Schizencephaly is also considered a disorder of cortical organization because the cortex surrounding the cleft is polymicrogyric.[1]

An important role in genesis of Schizencephaly is mutation in homeobox gene EMX2, a gene coding for transcription factor involved in expression of the gene. Several studies evidenced data suggesting that EMX2 gene may be involved in the modulation of cell proliferation of cortical neuroblasts and/or cell migration of postmitotic neurons, as it is known that these cells reach their final destination in the mature cortex according to their generation date. On the other hand, recent data demonstrate that EMX2 gene has no major role in schizencephaly.(8)

Children with closed-lip schizencephaly typically present with hemiparesis or motor delay, whereas patients with open-lip schizencephaly usually present with hydrocephalus or seizures. Patient with closed-lip schizencephaly are more likely to have mild-to-moderate neurologic deficit than those with open-lip type. Unilateral closed-lip schizencephaly is associated with the best neurodevelopmental outcome. Nearly, all patients with bilateral open-lip clefts have severe disabilities.(9) 


\section{REFERENCES:}

1. Granata T, Freri E, Caccia C, Setola V, Taroni F, Battaglia G. Schizencephaly: Clinical spectrum, epilepsy, and pathogenesis. J Child Neurol 2005; 20: 313-18.

2. Howe DT, Rankin J, Draper ES. Shizenzephaly prevalence, prenatal diagnosis and clues to etiology: A register- based study. Ultrasound Obstet Gynecol. 2012 Jan; 39(1):75-82. doi:10.1002/uog.9069.pub2011Dec5.

http://cortfoundation.org/cms/get-informed/types-ofmalformations/schizencephaly/

3. Yakovlev PI, Wadsworth RC. Schiz-encephalies: A study of the congenital clefts in the cerebral mantle. I. Clefts with fused lips. J Neuropathol Exp Neuro 1946; 5: 116-130.

4. Yakovlev PI, Wadsworth RC. Schiz-encephalies: A study of the congenital clefts in the cerebral mantle. II Clefts with hydro-cephalus and lips separated. J Neuropathol Exp Neurol 1946: 5: 169-206.
5. Guerrini R, Filippi T. Neuronal migration disorders, genetics, and epileptogenesis. J Child Neurol 2005; 20: 28799.

6. Iannetti P, Nigro G, Spalice A, Faiella A, Boncinelli E. Cytomegalovirus infection and schizencephaly: Case report. Ann Neurol 1998; 43: 123-27.

7. Gunny RS, Chong WKK. Paediatric Neuroradiology. In: Grainger \& Allison`s Diagnostic Radiology. 5 th Edition. Volume II. Churchill Livingstone Elsevier, 2008; 1660.

8. Merello E, Swanson E, De Marco P, Akhter M, Striano P, Rossi A, et al. No major role for the EMX2 gene in schizencephaly.

Am J Med Genet A 2008; 146A: 1142-50.

9. Robertson R, Caruso PA, Truwit CL et al Disorders of Brain Development. In: Magnetic Resonance Imaging of the Brain and Spine. Scott W. Atlas. 3 rd Edition. Lippincott Williams \& Wilkins, 2002;356-60. 